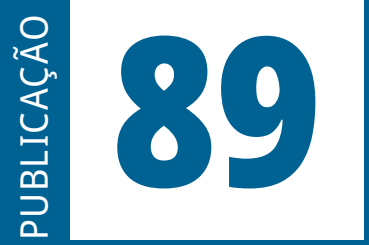

ISSN: 0101-9562

ISSN ELETRÔNICO: 2177-7055

SEQÜÊNCIA

Publicação do

Estudos jurídicos

e políticos

Programa de Pós-Graduação em Direito da UFSC

VOLUME 42 - ANO 2021 
SEQUÊNCIA - ESTUDOS JURÍDICOS E POLÍTICOS é uma publicação temática e de periodicidade quadrimestral, editada pelo Programa de Pós-Graduação Stricto Sensu em Direito da Universidade Federal de Santa Catarina - UFSC.

SEQUÊNCIA - ESTUDOS JURÍDICOS E POLÍTICOS is a thematic publication, printed every four months, edited by the Program in law of the Federal University of Santa Catarina - UFSC.

Versão eletrônica: http://www.periodicos.ufsc.br/index.php/sequencia

A publicação é indexada nas seguintes bases de dados e diretórios/

The Publication is indexed in the following databases and directories:

Base OJS

Base PKP

CCN (Catálogo Coletivo Nacional)

Dialnet

DOAJ (Directory of Open Access Journals)

EBSCOhost

Genamics Journalseek

ICAP (Indexação Compartilhada de Artigos de Periódicos)

Latindex

LivRe!

OJS
PKP
Portal de Periódicos UFSC
Portal do SEER
ProQuest
SciELO
Sherpa/Romeo
Sumarios.org
ULRICH'S
vLex

Ficha catalográfica

Seqüência: Estudos jurídicos e políticos. Universidade Federal de Santa Catarina.

Programa de Pós-Graduação em Direito. n.1 (janeiro 1980)-.

Florianópolis: Fundação José Boiteux. 1980-.

Publicação contínua

Resumo em português e inglês

Versão impressa ISSN 0101-9562

Versão on-line ISSN 2177-7055

1. Ciência jurídica. 2. Teoria política. 3. Filosoia do direito. 4. Periódicos.

I. Universidade Federal de Santa Catarina. Programa de Pós-graduação em

Direito

CDU 34(05)

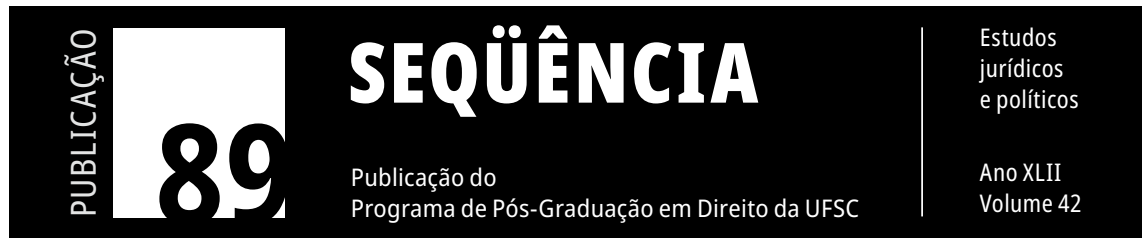




\title{
Corrupção na obtenção de contratos como argumento de defesa no caso Vantage v. Petrobras (2018): repercussões da operação lava jato no Brasil sobre a arbitragem comercial internacional
}

\section{Corruption in the procurement of contracts as a counterclaim in Vantage v. Petrobras (2018): repercussions of operation car wash in Brazil on international commercial arbitration}

\author{
Joana Stelzer ${ }^{1}$ \\ ${ }^{1}$ Universidade Federal de Santa Catarina, Florianópolis, Brasil \\ Alisson Guilherme Zeferino ${ }^{2}$ \\ ${ }^{2}$ Universidade Federal de Santa Catarina, Florianópolis, Brasil
}

RESUMO: Detalhou-se a repercussão da Operação Lava Jato no Brasil sobre a arbitragem comercial internacional no Caso Vantage v. Petrobras, de 2018, relativamente à defesa pautada em nulidades contratuais vinculadas à corrupção na obtenção do contrato basilar da relação jurídica. O problema de pesquisa consistiu na seguinte indagação: como se deu a repercussão da Lava Jato sobre a arbitragem comercial no caso Vantage v. Petrobras? Lançou-se a hipótese de que aludida repercussão teve alcance limitado e com parcial e possível prejuízo à defesa da Petrobras em esfera internacional. Abordou-se a negociação de acordo de fornecimento de serviços de perfuração de águas superprofundas por navio-sonda da Vantage à Petrobras, a força-tarefa da Lava Jato, bem como tratou-se do procedimento arbitral aberto pela Vantage a partir da rescisão unilateral do contrato de afretamento obtido mediante corrupção. A pesquisa caracterizou-se como qualitativa, de método indutivo e técnica descritiva, com recurso à análise bibliográfica. Concluiu-se que a Operação Lava Jato repercutiu na arbitragem internacional na medida em que o fruto de suas investigações e procedimentos de colaboração premiada motivaram a rescisão unilateral antecipada do pacto por violações contratuais, contestada 
pela Vantage, porém não influenciou a sentença arbitral a respeito das nulidades arguidas pela Petrobras.

PALAVRAS-ChAVE: Operação Lava Jato - Arbitragem comercial internacional - Corrupção na obtenção de contratos - Petrobras.

ABSTRACT: The main scope of the article is to detail the repercussions of Operation Car Wash in Brazil on international commercial arbitration procedures in Vantage v Petrobras (2018), with regards to the defense allegations that corruption in the securing of a contract deem it void or voidable. In this sense, it was wondered: how Car Wash reflected on commercial arbitration in Vantage v. Petrobras? The hypothesis is that its reflex was limited, with partial and possible prejudice to Petrobras' defense in the arbitration. The study exposes the procurement of an agreement to provide drilling services in deep waters by Vantage to Petrobras, the Car Wash task-force, and it also deals with the arbitral procedure initiated by Vantage upon unilateral termination of the leasing contract obtained through corruption. It is a qualitative research, conducted through the inductive method, which employs descriptive analysis and bibliographical review. We conclude that Operation Car Wash had repercussions on the international arbitration, consistent with the findings of the investigation and plea deals motivated the early termination for contractual breaches also, fought by Vantage, but it has not influenced the arbitral award with regards to contractual annulment counterclaims made by Petrobras.

KEYWORDS: Operation Car Wash - International commercial arbitration - Corruption in contract procurement - Petrobras.

\section{INTRODUÇÃO}

Os contornos e as nuances de um caso complexo envolvendo associação criminosa com vistas a oferecer a agentes públicos e políticos vantagens indevidas de modo a formalizar contratos vultosos com a Administração Pública formam o pano de fundo da presente pesquisa. Trata-se da descoberta de um grande esquema arregimentado para fraudar a concorrência internacional e beneficiar indevidamente empresas e interessados em contratar com importantes diretorias da transnacional empresa Petróleo Brasileiro S.A. (Petrobras).

Em 2013, antes mesmo da deflagração oficial da denominada Operação Lava Jato, que ocorreu em 2014, um contrato de US\$1,816 
bilhão pactuado em 2009 pela Petrobras Venezuela Investments \& Services (PVIS) e pela Vantage Deepwater Company, por meio do qual a PVIS afretou um navio-sonda para perfurar águas profundas no Golfo do México, desvelou a atividade criminosa reiterada no âmbito do Sistema Petrobras.

A relevância paradigmática desse caso e que justifica a presente pesquisa não está somente na descoberta de corrupção nas tratativas para a assinatura do contrato do navio-sonda registrado sob o nome Titanium Explorer. Igualmente, também não se resume em ter desacobertado ilícitos penais e ter permitido à Justiça brasileira atingir, bloquear e recuperar bens e somas em dinheiro de políticos do alto escalão e diretores de grandes empreiteiras, devolvendo-os aos cofres públicos. A derradeira justificativa está na logicidade impressa ao processo arbitral e de que maneira a lógica do Tribunal caminhou, abrindo precedente - porventura - para semelhantes demandas futuras.

O caso se revela de palpitante atualidade, uma vez que o contrato entre PVIS e Vantage, o qual tinha previsão para viger até dezembro de 2020, foi rescindido unilateralmente pela Petrobras em agosto de 2015 em decorrência de violações materiais do contrato, pela contratada, referentes a procedimentos falhos e economicamente prejudiciais no setor do petróleo. Acrescenta-se a esse motivo, como se pretende demonstrar, o próprio efeito da Operação Lava Jato consistente na impossibilidade de manter os ônus e bônus da contratação após o reconhecimento de que houve corrupção no processo negocial.

O problema de pesquisa consiste no seguinte questionamento: como ocorreu a repercussão da Operação Lava Jato sobre a arbitragem comercial no caso Vantage v. Petrobras relativamente ao argumento de defesa pautado em nulidade contratual? Elaborou-se hipótese de trabalho no sentido de que a repercussão da Operação Lava Jato teve alcance limitado, embora com parcial e possível prejuízo à defesa da Petrobras em esfera internacional.

Diante desse quadro, o objetivo geral busca detalhar a repercussão da Operação Lava Jato no Brasil sobre a arbitragem comercial 
internacional no Caso Vantage v. Petrobras relativamente à defesa pautada em nulidades contratuais vinculadas à corrupção na obtenção do contrato basilar da relação jurídica.

Especificamente, de modo a atingir o propósito delineado, procurou-se em sede de objetivos específicos: a) destacar a importância do jornalismo investigativo do caso, na medida que foi o embrião dos esforços institucionais para proceder à persecução penal dos suspeitos; b) relatar as tratativas na obtenção de contrato de prestação de serviços de sonda oceânica entre Vantage e Petrobras; c) discriminar a cadeia de contratos comerciais vinculada à controvérsia arbitral; e; d) especificar as alegações das partes e a conclusão do tribunal arbitral a respeito da defesa pautada em corrupção e suborno na obtenção do contrato.

Quanto à metodologia da pesquisa, possui natureza de pesquisa básica, pura, uma vez que forneceu os contornos epistemológicos de um dos mais emblemáticos cases que o Brasil já vivenciou, oportunizando conhecimento científico a guiar situações semelhantes no País ou no estrangeiro. Respeitante à abordagem do problema, tratou-se de pesquisa qualitativa, ao se ocupar da cognição e da interpretação dos fundamentos político-jurídicos que envolveram não somente as decisões judiciais e a sentença arbitral, mas a logicidade que a repercussão do caso teve (e que poderá ter em situações futuras). Do ponto de vista de seus fins, a pesquisa foi descritiva, ao detalhar de forma minuciosa o complexo encadeamento dos fatos e a multiplicidade de sujeitos envolvidos nas investigações da Lava Jato sobre a contratação da Vantage pela Petrobras na arbitragem comercial internacional. $\mathrm{O}$ método de abordagem foi indutivo, porquanto a pesquisa foi embasada (a) na exposição do caso de corrupção; (b) na demonstração de sua relação com auditoria interna na Petrobras; (c) na reunião dos principais aspectos da persecução penal de crimes do esquema desvelado pela Lava Jato; (d) no detalhamento dos temas controvertidos na arbitragem comercial, com destaque para a forma como as descobertas da Lava Jato influenciaram o entendimento do tribunal arbitral a respeito do tema das nulidades. Os resultados foram expostos exclusivamente em forma de textos. 


\section{A ELUCIDAÇÃO DE CORRUPÇÃO NA CONTRATAÇÃO DA VANTAGE PELA PETROBRAS: DA REVISTA ÉPOCA À LAVA JATO}

Muito antes que o brasileiro incluísse no seu cotidiano um sem número de menções a termos como força-tarefa, Lava Jato, condução coercitiva e também delação premiada, a investigação sobre possíveis ilícitos na condução de negociações de contratos do Sistema Petrobras ${ }^{1}$ foi fundamentalmente jornalístico. Trata-se, portanto, de evidenciar as origens do case, que - frise-se - não se engendrou pelas vias de uma investigação institucionalizada dos órgãos do Estado, mas, nas malhas da imprensa. Era o início da revelação sobre um dos maiores escândalos financeiros da história brasileira e mundial.

A longa narrativa já imbuída no imaginário dos brasileiros a respeito da Operação Lava $\mathrm{Jato}^{2}$ parece suprimir o protagonismo de personagens e o descortinar de situações fáticas de relevo que, em verdade, foram responsáveis por inaugurar um importante capítulo da história do País com relação à corrupção na Administração Pública.

As revelações sobre a contratação da Vantage Deepwater Company $^{3}$ pela Petrobras Venezuela Investments \& Services B.V. (PVIS),

1 O Sistema Petrobras, em termos de governança societária, compreende "a Petróleo Brasileiro S.A. e suas subsidiárias integrais, controladas, controladas em conjunto e coligadas onde a primeira, direta ou indiretamente, possua participação acionária" (PETROBRAS, 2015, p. 27).

2 O nome atribuído à operação faz referência aos estabelecimentos utilizados por uma das organizações criminosas inicialmente investigadas para movimentar valores ilicitamente, a saber, uma lavanderia e postos de combustíveis (POLÍCIA FEDERAL, 2014).

3 A Vantage Deepwater Company é uma companhia organizada e estabelecida sob as leis das Ilhas Cayman, integrante da Vantage Drilling International. A descrição veiculada pela diretoria desta última é a seguinte: "A Vantage, uma empresa isenta de impostos das Ilhas Cayman, é uma empreiteira de perfuração submarina, com uma frota própria de três embarcações de perfuração de águas ultraprofundas, a Platinum Explorer, a Titanium Explorer e a Tungsten Explorer, bem como quatro plataformas flutuantes ultra-premium Baker Marine Pacific Class 375. A atividade principal da Vantage é a contratação de unidades e equipamento de perfuração e equipes de trabalhadores mediante pagamento diário para a perfuração de poços de petróleo e de gás natural. 
subsidiária da Petróleo Brasileiro S.A. ${ }^{4}$ registrada na Holanda verificam-se no centro dessa complexa trama, posta a descoberto pela Revista Época. Com efeito, essas são as pistas iniciais e anteriores à Operação Lava Jato, a qual mirou esquemas contra a Petrobras e seus desdobramentos a partir da denominada terceira fase.

A cronologia do escândalo de corrupção ${ }^{5}$ teve início, portanto, em 12 de agosto de 2013, com a investigação jornalística de Diego Ecosteguy preparada para a edição 794 da Revista Época, intitulada 'A sombra do PMDB na Petrobras'. Esclareciam-se, então, as revelações

A Vantage também fornece serviços de supervisão de construção, e opera e gerencia unidades de perfuração de terceiros. Proprietária de uma frota de sete unidades de perfuração, a Vantage é provedora de serviços de perfuração offshore sob contrato para grandes empresas de petróleo e gás natural, nacionais e independentes de todo o mundo" (GLOBENEWSWIRE, 2015).

4 A Petróleo Brasileiro S.A., sociedade de economia mista criada pela Lei 2004 de 1953 , durante o governo de Getúlio Vargas, tem seu funcionamento autorizado pela Lei 9.478 de 1997, que revogou a normativa anterior e prevê, em seu artigo $4^{\circ}$ a atuação na execução do monopólio estatal estabelecido para a exploração de atividades de (i) pesquisa e lavra das jazidas de petróleo e gás natural e outros hidrocarbonetos fluidos; (ii) refinação de petróleo nacional ou estrangeiro; (iii) importação e exportação dos produtos e derivados básicos resultantes das atividades anteriores; e (iv) no transporte marítimo do petróleo bruto de origem nacional ou de derivados básicos de petróleo produzidos no País, bem como o transporte, por meio de conduto, de petróleo bruto, seus derivados e de gás natural (BRASIL, 1953; BRASIL, 1997). Ademais, “(...) a organização da sociedade de economia mista sob a forma de sociedade anônima é imposição que consta de lei de âmbito nacional, a saber, a Lei das Sociedades por Ações" de n. 6.404/76 (DI PIETRO, 2014, p. 523), o que dissipa eventuais dúvidas a respeito de sua estruturação por menção normativa alternante entre sociedade de economia mista, sociedade por ações e sociedade anônima.

5 Em ampliação do conteúdo legal contido na legislação brasileira, uma vez que o Sistema Petrobras envolve múltiplas jurisdições e regramentos concernentes à corrupção, que incluem, para além do Código Penal Brasileiro e a Lei 12.846/2013, o Foreign Corrupt Practices Act 1977 (FCPA) e o UK Bribery Act 2010, a corrupção é assim caracterizada: "Ação direta ou indireta, consistente em autorização, oferecimento, promessa, solicitação, aceitação, entrega ou recebimento de vantagem indevida, de natureza econômica ou não, envolvendo agentes públicos ou não, com o objetivo de que se pratique ou deixe de praticar determinado ato. A conduta pode ser tentada" (PETROBRAS, 2015, pp. $5,25-26)$. 
de João Augusto Rezende Henriques ${ }^{6}$ sobre, pelo menos, cinco negociações nas quais o operador afirmava ter ocorrido favorecimento indevido e pagamento de propina ${ }^{7}$ a membros do Partido do Movimento Democrático Brasileiro (PMDB) e também do Partido dos Trabalhadores (PT) como decorrência do sucesso na conclusão de contratos de compra e venda e de prestação de serviços.

O entrevistado (considerado lobista) relatara que o então diretor internacional da Petrobras, Jorge Zelada, indicado ao cargo em 2008 , era apadrinhado do partido cujos interesses representava junto a empresários estrangeiros e que o ajuste de propina a ser repassada a alguns de seus membros ocorria em diversos contratos da área coordenada por Zelada. A partir disso, João Augusto transferia até $70 \%$ do dinheiro arrecadado de empresários que formalizavam, por seu intermédio, contratos com a Petrobras. O restante do valor era repartido com colaboradores internos que permitiam a tramitação dos papéis observando esse esquema (Ecosteguy, 2013).

Cinco negociações perfizeram o que redundaria em um escândalo maior na continuidade. A primeira referia-se à venda de uma refinaria da Petrobras Argentina (PESA) em San Lorenzo, em 2010, por US\$ 110 milhões a Cristóbal Lopez. Segundo o relato, o acordo inicial (reduzido a termo) era para que um valor indevido de US\$ 10 milhões fosse repassado por uma empresa sediada no Uruguai a um intermediador brasileiro. As outras negociações giraram sobre um contrato de US $\$ 860$ milhões da área internacional da Petrobras

${ }^{6}$ João Augusto foi diretor de uma empresa de combustíveis da Petrobras, a BR Distribuidora, na década de 90 . Seu nome chegou a ser indicado para a diretoria internacional da Petrobras, em 2008, porém uma condenação do Tribunal de Contas da União ao pagamento de vultosa multa por irregularidades em sua atuação na BR tornou sua aprovação, pela Casa Civil, impossível. Em substituição, ingressou no posto Jorge Luiz Zelada. João Augusto, contudo, seguiu intermediando negociações como "diretor de fato" da diretoria internacional (ECOSTEGUY, 2013).

7 Propina, no Sistema Petrobras, "é um pagamento, um presente, um favor oferecido ou dado com vistas a perverter o julgamento ou influenciar a conduta de uma pessoa que esteja em certa posição de confiança” (PETROBRAS, 2015, p. 27). 
com a empreiteira Odebrecht que teria rendido propina de US $\$ 11$ milhões; bem como a "compra de um campo [pela Pebrobras] na Namíbia, operação encaminhada depois de ele ter fechado comissão com a empresa que detinha o controle desse campo", e a venda da participação societária "que a Petrobras [tinha] numa distribuidora de energia na Argentina” (Ecosteguy, 2013).

$\mathrm{Na}$ continuidade, veio à tona a intermediação de João Augusto para que a Petrobras alugasse o navio-sonda Titanium Explorer, da Vantage Deepwater Company:

Nem todas as operações eram tão difíceis quanto a venda da refinaria de San Lorenzo. No mesmo período, João Augusto diz que fechou um contrato de US\$ 1,6 bilhão para que a Petrobras alugasse o navio-sonda Titanium Explorer, da empresa Vantage. O contrato rendeu uma comissão de US\$ 14,5 milhões, que deveria ser paga em três parcelas. Segundo João Augusto, a primeira foi paga ainda no começo de 2009; a segunda, em seguida. A terceira, diz ele, não foi paga, em razão de uma briga societária na Vantage. (...) "Repassei US\$ 10 milhões ao PMDB”, diz (Ecosteguy, 2013).

Como se depreende da denúncia, o afretamento do navio-sonda Titanium Explorer teria ocorrido mediante corrupção na medida em que membros do partido teriam efetivamente se beneficiado de US\$10 milhões relativos à propina exigida da Vantage para fechar o contrato de significativo valor.

Avançando-se pela cronologia fática, em 13 de agosto de 2013, uma Comissão Interna de Apuração (CIA) intitulada CIA Época foi constituída pela Presidência da companhia com o objetivo de "confirmar a atuação do denunciante, Sr. João Augusto; apurar possíveis prejuízos sofridos pela Petrobras; identificar desvios de processos; e apontar a responsabilidade trabalhista dos envolvidos em eventuais irregularidades" (CIA, 2013, pp. 1-2).

O relatório final da CIA foi remetido à Presidência da Petrobras em 25 de outubro de 2013, no qual apontaram-se as seguintes 
descobertas com relação à contratação do Titanium Explorer: em 4 de agosto de 2008, um gerente executivo da diretoria internacional solicitara ao diretor (Zelada), autorização para buscar por empresas brasileiras e estrangeiras interessadas em fornecer à companhia duas unidades de perfuração de águas ultraprofundas. Em 15 de agosto, foi formada comissão de negociação com quatro colaboradores especificamente para esse processo de contratação. Com a fixação de critérios de pontuação para selecionar a melhor das propostas apresentadas, em 16 de outubro a comissão emitiu seu relatório, no qual a Pride International figurava no topo da lista. Havia uma ressalva que, por ausência de tempo, propostas deixaram de ser avaliadas, dentre as quais da Vantage Deepwater Company (CIA, 2013, p. 23-24).

$\mathrm{Na}$ continuidade (e de acordo com o relatório da CIA), houve violação a processos prescritos pela necessidade de governança corporativa e controle interno de agentes e negociações. Zelada determinou a inclusão de propostas não analisadas no ranking elaborado. Em 29 de outubro, e desse ponto em diante, a comissão de negociação deixou de atuar no processo, sendo certo que a sua condução foi assumida por Eduardo Vaz Costa Musa. Musa, então, recebeu Paul Alfred Bragg, executivo da Vantage, que apresentou proposta para o afretamento de suas unidades, Platinum e Titanium Explorers, em 3 de dezembro. Embora a Pride permanecesse acima na classificação das ofertas, Zelada decidiu que a diretoria deveria contratar apenas um navio, e não dois. Sem embargo, reuniões posteriores com executivos da Vantage motivaram-lhes a modificar sua proposta outras duas vezes. Dessa feita, o ranqueamento final estampou o Titanium Explorer com a melhor pontuação dentre as catorze sondas listadas. Ato contínuo, a diretoria executiva aprovou o resultado das negociações e o contrato entre Vantage Deepwater Company e Petrobras Venezuela Investments \& Services B.V ${ }^{8}$ foi assinado em 4 de fevereiro de 2009, no valor de US\$1.816.093,00 (CIA, 2013, p. 26-27).

8 De acordo com a CIA, não existiam regulamentos, na época, que impedissem a negociação de contratos pela Petróleo Brasileiro S.A., no Brasil, em nome e benefício 
Interessante notar como, num primeiro momento, ${ }^{9}$ os auditores responsáveis por apurar essas denúncias não visualizaram prejuízo financeiro à empresa sob o argumento de que o valor total ajustado para o contrato teria observado a precificação usual do mercado para operações semelhantes. Reconheceram que a reportagem da Revista Época e os fatos apurados possuíam correlações, assumindo a possibilidade de João Augusto ter intermediado negócios da companhia. Ao final, recomendaram a adoção de medidas disciplinares quanto ao pessoal envolvido e a remessa do relatório final ao Ministério Público (CIA, 2013, p. 46).

Unificadas em 17 de março de 2014, quatro operações conduzidas pela Polícia Federal, nomeadas Dolce Vita, Bidone, Casablanca e Lava Jato tratavam da investigação de crimes contra a ordem financeira e desvios de recursos públicos em diversas localidades do território nacional. Como resultado das referidas investigações, emergiu a Operação Lava Jato, ${ }^{10}$ ou Car Wash, considerada a maior ação policial e judicial envolvendo corrupção e lavagem de capitais deflagrada pela máquina estatal no País (Polícia Federal, 2016; Ministério Público Federal, 2019a).

de subsidiárias ou controladas localizadas no exterior, razão pela qual esse procedimento de contratação por pessoa jurídica diversa foi classificado como simplificado, mas desconforme com boas práticas de governança pelo desrespeito à hierarquia de diretorias e competências específicas, bem como por inexistir relatório final da comissão montada para acompanhar os trabalhos dessas tratativas em especial (CIA, 2013, p. 27).

9 De acordo com o Parquet, em auditoria motivada pelas descobertas da Lava Jato, houve mais indícios de inadequação às normas internas e violação de leis criminais pela diretoria internacional no caso Vantage: "manipulações, a pedido de Zelada, dos estudos que indicavam a necessidade da contratação deste navio-sonda; falta de governança corporativa adequada ante o não registro de reuniões de negociações; falta de uniformidade de parâmetros de comparação entre as propostas; falta de prova de análise da economicidade da redução de taxa em troca de aumento de prazo contratual quando da realização do aditivo contratual; e concessão de extensão de prazo para apresentação do navio-sonda sem aplicação de penalidade" (MINISTÉRIO PÚBLICO FEDERAL, 2015).

10 O nome atribuído à operação faz referência aos estabelecimentos utilizados por uma das organizações criminosas para movimentar valores ilicitamente, a saber, uma lavanderia e postos de combustíveis (POLÍCIA FEDERAL, 2014). 
Organizada em fases, a Lava Jato focalizou inicialmente a ação de agentes do mercado clandestino de câmbio - doleiros, na terminologia empregada no meio -, por condutas previstas na Lei n. 7.492/86, a qual rege a persecução penal de ilícitos praticados contra o sistema financeiro nacional. O Conselho de Controle de Atividades Financeiras $(\mathrm{COAF})^{11}$ identificou atipicidade monetária na movimentação de mais de $\mathrm{R} \$ 10$ bilhões por esses operadores, que pela cotação de março de 2014, atingia, em dólares, US $\$ 4,25$ bilhões. Na primeira fase, foram cumpridos mais de oitenta mandados de busca e apreensão, dezoito mandados de prisão preventiva, dez de prisão temporária e múltiplas conduções coercitivas em dezessete municípios de sete unidades federativas. Na mesma oportunidade, a Justiça Federal determinou o sequestro de bens adquiridos mediante práticas ilícitas, além do bloqueio de contas bancárias e aplicações financeiras, tudo em decorrência da conexão estabelecida entre os registros contábeis das pessoas naturais e jurídicas sob investigação e crimes como tráfico internacional de narcóticos, sonegação fiscal, contrabando de pedras preciosas e corrupção (Polícia Federal, 2014).

O envolvimento do mercado clandestino de câmbio com a Administração Pública Federal, salienta-se, passou a ser investigado oficialmente em novembro de 2014, na sétima fase da Lava Jato, esta, em especial, nomeada Operação Juízo Final, motivada pela descoberta do papel ativo dos doleiros na facilitação do repasse de propinas pactuadas para fraudar processos licitatórios e favorecer determinadas

11 Dentre as atribuições do conselho, integrante da organização fazendária, está a produção de inteligência acerca de movimentações financeiras de modo a proteger o sistema econômico da lavagem de capitais e do financiamento do terrorismo pelo apontamento de suspeita em atividades registradas e remessa dos casos às autoridades competentes. Em dezembro de 2018, o presidente do conselho, Antonio Carlos Ferreira de Sousa, divulgou balanço que recapitulou o histórico de Relatórios de Inteligência Financeira já produzidos e remetidos pelo órgão em número que se aproxima dos quarenta mil. Somente em 2018, por ação conjunta, logrou-se bloquear judicialmente mais de R \$ 36 milhões, ou, pela cotação de dezembro de 2018, US\$9,18 milhões, tanto no Brasil quanto no exterior em razão de crimes (COAF, 2018). 
organizações na celebração de contratos públicos com setores da Petróleo Brasileiro S.A. A partir dos resultados das buscas conduzidas e pelo êxito nos procedimentos de colaboração premiada de alguns réus, ${ }^{12}$ restou evidenciado o liame político entre os intermediadores dos contratos vinculados à Administração Pública e grandes empreiteiras (Polícia Federal, 2016; Polícia Federal, 2018).

O esquema criminoso de contratações revelado pela dinâmica entre empresas estrangeiras, pessoas inscritas nos quadros da Petrobras, operadores financeiros e agentes políticos, também empregado na contratação da Vantage, funcionou fundamentalmente da seguinte maneira: as empreiteiras ajustavam propina com diretores da Petrobras e políticos, em valores variáveis entre um e cinco por cento da monta de contratos superfaturados, transformadas em dinheiro limpo e movimentadas por doleiros, de modo a controlar o momento oportuno para que sociedades empresárias obtivessem negócios com a gigante brasileira do petróleo. A restrição dos convidados inseria a empreiteira previamente ajustada para vencer o processo licitatório na lista de participantes, que então movimentava somas em espécie no exterior até as mãos dos doleiros por intermédio de contas registradas em nome de empresas de fachada. Estes, por sua vez, eram encarregados de reverter as quantias, em espécie ou bens, aos indivíduos que interferiam criminosamente em licitações ou contratos. ${ }^{13}$ Dentre as

12 Sobre os acordos de colaboração firmados entre as autoridades ministeriais responsáveis pela acusação e os réus, ver ROSA, Alexandre Morais da. Para entender a delação premiada pela teoria dos jogos: táticas e estratégias do negócio jurídico. Florianópolis, EModara, 2017.

13 Considerando-se a abertura da septuagésima fase da Lava Jato e o decurso temporal de mais de seis anos desde a deflagração judicial da fase primeva da força-tarefa, quando se recapitulava pelo menos uma década de infrações puníveis, dados atualizados colocavam em perspectiva o massivo movimento da máquina estatal para buscar a condenação dos indivíduos e organizações nas searas respectivas e a reparação dos prejuízos produzidos aos cofres públicos, estimado em bilhões de reais. Já foram mais de 210 condenações em primeira instância, computadas sentenças penais condenatórias da Justiça Federal em Curitiba, São Paulo e Rio de Janeiro. Somados, excedem a 1500 os processos distribuídos aos Tribunais Regionais Federais da Segunda e Quarta Região. No STF há 
múltiplas diretorias da Petrobras, a de abastecimento, a de serviços e a internacional foram as mais utilizadas para fortalecer esse esquema criminoso (Ministério Público Federal, 2019a).

No que concerne às operações internacionais da Petrobras, estas eram desenvolvidas por meio de subsidiárias e de parcerias. ${ }^{14}$ A presença deslocalizada ${ }^{15}$ e a representatividade em seus campos de atuação inscreviam a Petrobras na categoria de player globa $1^{16} \mathrm{e}$, nesse âmbito, em razão da imagem pública afetada pelos crimes cometidos nas gestões de diretorias importantes para a manutenção e projeção dos

126 denunciados. No STJ, sete. O valor que se estima recuperar é de R \$14,7 bilhões, ou, pela cotação da data de publicação do dado, US\$2,62 bilhões (MINISTÉRIO PÚBLICO FEDERAL, 2019a).

14 A base legal para a exploração do monopólio estatal por entidades jurídicas diferentes da Petróleo Brasileiro S.A consiste na Lei 9.478, de 1997, que autorizou sua criação e, em seu Artigo 61, \ $2^{\circ}$, previu: "A Petrobras, diretamente ou por intermédio de suas subsidiárias, associada ou não a terceiros, poderá exercer, fora do território nacional, qualquer uma das atividades integrantes de seu objeto social." Nesse palmilhar, o Artigo 64 autorizou a associação das subsidiárias a outras empresas independentemente de qual delas detivesse capital majoritário na parceria. A companhia foi, inclusive, ordenada, no Artigo 65, a “(...) constituir uma subsidiária com atribuições específicas de operar e construir seus dutos, terminais marítimos e embarcações para transporte de petróleo, seus derivados e gás natural" (BRASIL, 1997).

15 A trajetória internacional foi iniciada pela exploração de vantagens comerciais na Colômbia, em 1972. Além dessa operação, na América do Sul, em atividade ou em processo de desinvestimento, a Petrobras mantinha interesses e ativos na Argentina, Bolívia, Chile, Paraguai e Uruguai. Estados Unidos e México faziam parte do portfólio na América do Norte, enquanto Angola, Nigéria e Tanzânia contavam com uma joint venture da empresa no continente africano. Na Europa, estrategicamente localizada na Holanda e no Reino Unido, restava concentrada a gestão financeira dos seus negócios pelo mundo. China, Japão e Singapura representavam, na Ásia, novas oportunidades pela criação de segmentos da companhia com acesso à Índia e ao Oriente Médio (PETROBRAS, 2019a).

16 A afirmação tem por base a atuação transnacional do Sistema Petrobras. No campo teórico, "o fenômeno da transnacionalização é multifacetado, complexo, polêmico e encontra resistências para ser aceito como realidade cotidiana. Algumas características, contudo, podem ser evidenciadas para avaliar o fenômeno, a exemplo da desterritorialização das relações humanas e de produção, do fato da economia transnacionalizada ser capitalista ao extremo e do abalo na soberania dos Estados, motivando a emergência de novos sujeitos no palco mundial" (AUTOR, p. 25). 
negócios, os prejuízos econômicos que se seguiram atingiram tanto a companhia e seus investidores quanto a sociedade brasileira. O Relatório Anual de 2018, ao passo que celebrava a melhor performance desde 2014 e o retorno à posição de maior companhia na América Latina pela capitalização, em fevereiro de 2019, em valor superior a US\$ 100 bilhões, demonstrava haver aspectos positivos tão somente na comparação da companhia com sua própria posição histórica, consistente na "interrupção de quatro anos seguidos de prejuízos", porquanto diante da indústria petroleira global, o resultado atingido em muito se distanciava do desejável, fruto da má gestão inquinada pelos crimes perpetrados. (Petrobras, 2019b, p. 4).

Como apurado pela Justiça brasileira no transcurso da Ação Penal No 5039475-50.2015.4.04.7000/PR, ajuizada perante a Justiça Federal em Curitiba a partir de denúncia oferecida pelo Ministério Público Federal, o esquema por trás da contratação do navio-sonda envolveu uma promessa de pagamento de propina no valor de US $\$ 31$ milhões, e não de US\$14,5 milhões, como denunciado inicialmente. A partir da assinatura de acordo de colaboração premiada com o intermediador da Vantage, Hamylton Pinheiro Padilha Junior, evidenciou-se que o ajuste de propina ocorreu por meio de dois contratos, de Brokerage and Commission Agreement, de US\$15,5 milhões cada, firmados para fornecer as vantagens indevidas e influenciar os agentes públicos a afretar o Titanium Explorer. Restou esclarecido, também, que o navio, em verdade, era de propriedade de Taiwan Maritime Transportation Co. Ltd., (TMT), chinesa, de quem a Vantage afretaria o navio para então fornecê-lo à Petrobras, e que o diretor da TMT, Nobu Su, teve envolvimento no repasse da propina. Tal qual no caso do operador João Augusto, Hamylton Padilha também deixou de receber o terceiro dos pagamentos ilícitos a que se comprometeu a Vantage (Justiça Federal, 2016).

Quanto às condenações a penas restritivas de liberdade no curso da ação penal identificada acima: a) Jorge Zelada teve imputação de pena de doze anos e dois meses de reclusão pelos crimes de corrupção 
passiva e lavagem de capitais; b) João Augusto obteve pena de seis anos e oito meses de reclusão por corrupção passiva; c) A dosimetria aplicada a Eduardo Musa por corrupção passiva e lavagem de capitais atingiu pena de dez anos de reclusão; d) Hamylton Pinheiro foi condenado por corrupção ativa e lavagem de capitais a cumprir pena de oito anos de reclusão (Justiça Federal, 2016).

A relevância das descobertas da Lava Jato não se resumem somente ao contexto penal brasileiro e nesse ponto justifica-se a descrição supra: com o encerramento unilateral do contrato de 2009 celebrado com a Vantage, por parte do Sistema Petrobras, em 2017, teve origem uma controvérsia ${ }^{17}$ comercial levada à resolução por meio da arbitragem internacional na qual, como se pretende detalhar a seguir, em sua argumentação defensiva, a Petrobras alegou que a corrupção na obtenção do contrato, desvelada pela Operação Lava Jato, o tornaria nulo de pleno direito, ou então anulável. Era, portanto, uma tentativa de amparar em parâmetros legais a rescisão unilateral e evitar prejuízo financeiro pelo modo escolhido para encerrar suas relações mercadológicas e operacionais com a Vantage. Nesses termos, importa verificar a repercussão das descobertas da Lava Jato sobre o desenvolvimento da arbitragem comercial internacional no caso Vantage v. Petrobras.

\section{A CONTROVÉRSIA ARBITRAL ENTRE VANTAGE E PETROBRAS E A REPERCUSSÃO DA LAVA JATO SOBRE O CASO}

Em 2 de julho de 2018, a Vantage Drilling International veio a público informar ter vencido procedimento arbitral iniciado pela

\footnotetext{
17 Para Entelman, que teoriza sobre a dinâmica da interação conflitual, "o conflito é um processo dinâmico, sujeito à permanente alteração de todos os seus elementos. À medida que se desenvolve seu devir, mudam as percepções e as atitudes dos atores que, em consequência, modificam suas condutas, tomam novas decisões estratégicas sobre o uso dos recursos que integram seu poder e, frequentemente, chegam a ampliar, reduzir, separar ou fundir seus objetivos" (, p. 173).
} 
Vantage Deepwater Company e Vantage Deepwater Drilling, Inc. ${ }^{18}$ contra a Petróleo Brasileiro S.A. e suas subsidiárias, Petrobras America, Inc. (PAI) e Petrobras Venezuela Investments \& Services, BV (PVIS), pelo encerramento unilateral de contrato de fornecimento de serviços de perfuração firmado em fevereiro de 2009 e previsto para viger até dezembro de 2020. Por meio da sentença arbitral concluída em Houston, Texas, em 29 de junho de 2018, a Petrobras foi condenada ao pagamento de US\$ 615,62 milhões às empresas demandantes por antecipar o término do contrato sem justificativa ou desembolso da quantia devida pela totalidade do período contratual, além de US\$ 6,4 milhões pela inadimplência de invoices, ${ }^{19}$ valor que, pela cotação da moeda americana, na época, superava $\mathrm{R} \$ 2,4$ bilhões antes mesmo da contabilização das custas finais do tribunal (Globenewswire, 2018).

Em 3 de julho de 2018, a Petrobras divulgou fato relevante aos seus investidores para comunicar o resultado da arbitragem e da intenção de questionar a decisão do painel constituído sob os auspícios do International Centre for Dispute Resolution (ICDR), da American Arbitration Association (AAA), por tratar-se de decisum emitido por maioria, e não por unanimidade, e por considerar que imperativos procedimentais como a imparcialidade e o devido processo legal foram ignorados no julgamento do caso, o que prejudicou a apresentação de sua defesa. Ademais, justificou ter encerrado a relação jurídica antecipadamente por graves falhas operacionais da Vantage e que o contrato foi, como revelaram as investigações da Operação Lava Jato, obtido mediante corrupção (Petrobras, 2018a).

18 No procedimento arbitral, as empresas foram identificadas como Vantage Deepwater Company, uma companhia organizada e estabelecida sob as leis das Ilhas Cayman, e Vantage Deepwater Drilling, Inc., uma corporação com escritório registrado em Houston, Texas (ICDR, 2018, p. 1).

19 De acordo com a ferramenta Lexicon, o invoice é a conta ou fatura do vendedor de um bem ou provedor de um serviço por meio da qual se demanda o pagamento do comprador ou contratante (FINANCIAL TIMES LEXICON, 2019). 
Em respeito aos limites propostos à presente pesquisa, nessa seção buscar-se-á discriminar a cadeia de contratos vinculada à controvérsia arbitral; expor as justificativas da Petrobras para encerrar unilateralmente - e antes do termo final - o contrato de afretamento do Titanium Explorer com a Vantage; descrever o procedimento arbitral em linhas gerais e focalizar a defesa da Petrobras com fundamento na anulabilidade do pacto primevo, calcada em sua obtenção mediante corrupção e suborno para, a partir do arrazoado do tribunal, investigar qual foi a repercussão da Operação Lava Jato sobre aquele procedimento.

Destarte, anota-se que a arbitragem comercial observou o sigilo ${ }^{20}$ que é corriqueiro nesses procedimentos e, por essa razão, a existência do processo, enquanto tramitou, não foi amplamente divulgada, de sorte que o acesso ao conteúdo da sentença arbitral ${ }^{21}$ só foi possível porque a Vantage protocolou a Civil Action no. 18-cv-2246, em 2 de julho de 2018, perante a Corte Distrital dos Estados Unidos, no Distrito Sul do Texas, junto à Divisão de Houston, ação por meio da qual peticionou a confirmação da sentença arbitral que lhe fora favorável (ICDR, 2018).

20 Ao se debruçar sobre a temática da relação do Mercosul com a arbitragem comercial internacional, Stersi chama a atenção para o seu caráter confidencial, quando aduz que o sigilo é a regra respeitada nessa área, bem como que "o conhecimento do litígio fica restrito às partes e ao árbitro, inexistindo publicidade no que tange às provas produzidas, ao valor econômico do conflito, à razão da disputa, aos reflexos econômicos da controvérsia, etc." (STERSI, 1996, p. 133).

21 As sentenças arbitrais são consideradas importantes "por marcarem o fim de uma fase procedimental, seja de uma arbitragem que não vence o estágio jurisdicional, seja de uma que escalou até o mérito (...) é a decisão por meio da qual os árbitros comunicam o resultado da análise da [jurisdição e] capacidade, dos argumentos, exceções e pedidos das partes em uma controvérsia. As formalidades que imperam sobre esses documentos variam de acordo com a seleção do painel arbitral, inclusive a respeito da possibilidade de revisão ou anulação após sua prolação e remessa às partes (AUTOR, p. 68). Interessante notar, ademais, que na arbitragem internacional, as partes podem fixar parâmetros para conduzir a edição das sentenças que lhes serão remetidas, expressão de um grau de liberdade certamente não visualizado no âmbito da jurisdição estatal (SANTOS, 1996, p. 165-167). 
Não obstante, pela obrigatoriedade de prestação de contas, a Petrobras havia inserido em seu relatório de demonstração financeira de 2018 informações limitadas a respeito da disputa, porém nesse documento já indicava aos acionistas e controladores que o procedimento seguiria com a oitiva de testemunhas e alegações finais das partes. Ademais, estimava o custo total, em perdas para a empresa, de US\$ 403 milhões (Petrobras, 2018b, p. 67).

Para esclarecer a estratégia do grupo demandado na arbitragem, e sua apreciação e interpretação pelo tribunal, é salutar pormenorizar a cadeia contratual e seu objeto.

Tem-se originariamente o Acordo para a Provisão de Serviços de Perfuração, datado de 4 de fevereiro de 2009, como explicitado, acedido pela Vantage Deepwater Drilling Inc. (VDDI) e Petrobras Venezuela Investments \& Services BV (PVIS). ${ }^{22}$ Esse acordo foi objeto de três emendas e três novações. A primeira emenda ocorreu ainda em 2009, a segunda em 2012 e a terceira em 2013. As novações foram firmadas em 2012, 2013 e 2014. Desde a primeira novação houve inclusão ou substituição de subsidiárias do Sistema Petrobras no contrato de prestação de serviços e também de terceiras empresas. Na primeira novação, assumiu o contrato a Petrobras America Inc (PAI). Na segunda, Ophir Holdings Limited. A terceira novação foi procedida pelas sociedades empresárias PVIS, PAI, VDDI, Vantage Deepwater Company (VDEEP) e Vantage Driller VI CO. (VDVI), o que demonstra a pluralidade de contratantes na cadeia. As novações e emendas não alteraram a previsão de termo final (ICDR, 2018, pp. 3-4).

22 Tratando de regime público e privado na Administração Pública, Di Pietro (2014, p. 60) anota que a opção por um outro é feita ou pela Constituição, ou por lei, e que ao legislador não foi concedido direito de optar, no que concerne a sociedades de economia mista e suas subsidiárias: "quando este [o legislador] instituir, por lei, uma entidade para desempenhar atividade econômica, terá que submetê-la ao direito privado." A partir dessas considerações, embora celebrado com ente da Administração, admite-se a caracterização do contrato da Vantage com a Petrobras como comercial e sujeito, com relação às obrigações mutuamente assumidas com a Vantage, ao direito privado. 
O afretamento contratado pela taxa diária de US $\$ 490$ mil e $12,5 \%$ de bônus tinha previsão para durar oito anos, até 7 de dezembro de 2020, com sua instalação e operação no Golfo do México. Entretanto, em 31 de agosto de 2015, ocorreu a rescisão unilateral, aproximadamente cinco anos e três meses antes do termo ajustado. A intenção de arbitrar foi comunicada pelas demandantes às demandadas no mesmo dia. Ao se manifestar no litígio, a Vantage requereu compensação pecuniária em valor calculado pelo método direct benefit-of-the-bargain damages ${ }^{23}$ em US $\$ 560,2$ milhões, acrescidos de juros pré e pós sentença (ICDR, 2018, pp. 6-7, 48).

No procedimento arbitral, diferentemente das manifestações extremamente breves da Petrobras na mídia, necessária e naturalmente vieram a lume as justificativas legais sustentadas pela defesa técnica da companhia, divididas em dois grupos: a) a violação material do contrato decorrente da corrupção no processo negocial que culminou em sua obtenção, e; b) a persistente falha da Vantage em adequar-se às melhores práticas no ramo de petróleo e gás, explicitada em dois episódios nos quais "a Vantage falhou em monitorar de maneira apropriada o volume de fluidos, detectar perdas, e dar a devida notificação" (ICDR, 2018, p. 50).

Focalizando-se a defesa pautada nas ilicitudes performadas pelos representantes tanto da Petrobras quanto da Vantage de modo a assegurar a contratação do navio-sonda, averiguadas no transcurso da Operação Lava Jato no Brasil, as demandadas sustentaram, na arbitragem comercial, que as práticas também configuraram violações de cláusulas contratuais pelas demandantes. Isso, segundo a Petrobras, ocorreu pelo pagamento de verbas ilícitas a oficiais do governo, o que tornaria o contrato nulo ou anulável, e sujeito a rescisão, inclusive por

23 De acordo com os árbitros, as partes convergiram quanto à definição do termo que indica o cálculo dos danos pelo valor que a parte que não deu causa ao encerramento ou à quebra do contrato teria recebido, subtraindo-se dessa cifra os custos que aquela mesma parte deixou de suportar pela inexecução forçada de sua parcela de obrigações (ICDR, 2018, p. 86). 
indução fraudulenta à negociação. Ainda, que a diretoria da Vantage deu assistência para, ou conscientemente evitou se inteirar da quebra do dever fiduciário, e que houve falsidade material nas garantias fornecidas pela contratada, a exemplo da propriedade do navio-sonda, que em verdade era da TMT. Arrematou alegando ter suportado danos indenizáveis superiores a US\$ 100 milhões (ICDR, 2018, p. 67/84).

As demandantes, por sua vez, aduziram que o contrato era válido; que o ônus da prova permanecia com a Petrobras para convencer o tribunal de que pagamentos ilícitos foram feitos ou oferecidos a seus empregados, com conhecimento da Vantage - e desconhecidos da própria Petrobras -, com o objetivo de induzir a assinatura do pacto inicial. Em suma, defenderam que não houve produção de provas que evidenciassem ao tribunal as violações contratuais mencionadas, nem mesmo detalhamento de danos passíveis de indenização (ICDR, 2018, p. 70).

Todas as alegações da Petrobras foram rejeitadas, no mérito, pelo tribunal.

A apreciação do caso e das alegações sobre corrupção e suborno, conectadas diretamente com as afirmações de nulidade, anulabilidade ou rescisão contratual levou primariamente em consideração a cronologia por trás da cadeia de contratos, desde o primeiro acordo, firmado em fevereiro de 2009, até a terceira novação, formalizada em outubro de 2014, e as pessoas jurídicas signatárias desses instrumentos. Depois, o tribunal ponderou o conhecimento dos crimes pela Petrobras e o direito aplicável à remediação da situação de desconformidade legal por parte da pessoa jurídica vítima de um tal esquema criminoso.

Adianta-se que na sentença arbitral e nos anexos em que as partes submeteram aos árbitros a síntese de seus argumentos, inexiste qualquer menção expressa à Operação Lava Jato.

Mencionou-se, na sentença, que as demandantes chamaram atenção para o fato de a única testemunha da Petrobras levada a prestar depoimento a respeito do contexto da corrupção e suborno ter sido Hamylton Padilha, pessoa em quem, segundo elas, o juízo arbitral não 
podia confiar, já que ele teria interesse em mentir no procedimento, supostamente incentivado pela possibilidade de ter sua pena reduzida no Brasil. Adiante, ao listar alegações das demandadas, a sentença mencionou um julgamento da Justiça Federal de 2016. Para elas, o julgado constituía "prova conclusiva do suborno das demandantes" (ICDR, 2018, p. 58).

Tratava-se, portanto, de genuíno documento da Lava Jato, e a considerando-se a indicação do ano e o contexto em que foi mencionado, que o elemento de prova produzido foi a sentença penal condenatória de Jorge Zelada, João Augusto, Eduardo Musa e Hamylton Pinheiro (Ação Penal No 5039475-50.2015.4.04.7000/PR, aludida anteriormente), assinada em 1 de fevereiro de 2016 (JustiçA Federal, 2016).

Não se ignora a possibilidade de que no decurso do procedimento, em audiências, documentos ou sustentações orais tenham, de fato, ocorrido menções expressas à Lava Jato e à importância de se levar em consideração o que a Justiça brasileira apurou.

Todavia, o que é digno de nota, é que a sentença arbitral geralmente cobre suficientemente o desenvolvimento do procedimento e que os elementos colacionados ao processo têm seu valor probante apontado ou descartado textualmente pelo tribunal. Grave, porém, é que no entendimento do tribunal arbitral, deixou a Petrobras de fornecer provas do que ela própria aduziu como justificativas legais para o encerramento unilateral da relação comercial com a Vantage, a respeito, portanto, do pagamento de propina e das falhas técnicas em decorrência das quais afirmou ter experimentado perdas financeiras.

Especificamente, o tribunal elaborou seu arrazoado com fundamento no impedimento, que operou contra a Petrobras para exercer seu direito, na condição de vítima, à anulação do contrato firmado em fevereiro de 2009. À base do raciocínio jurídico figurou a cadeia contratual, como explicitado. Com a assinatura de novações ao pacto primitivo (relembre-se, a primeira novação ocorreu em 18 de abril de 2012, a segunda em 20 de dezembro de 2013 e, finalmente, a terceira 
em 27 de outubro de 2014), o tribunal concluiu que a Petrobras, caso tivesse comprovado suas alegações de suborno e corrupção perante o painel arbitral - o que não fez - somente poderia ter exercido seu direito à anulação do pacto inicial até a segunda novação. A razão: em 20 de dezembro de 2013 a PVIS e a VDEEP novaram o contrato a pessoas jurídicas diversas, PAI e VDDI, quando a Petróleo Brasileiro S.A. já tinha conhecimento do relatório final da CIA Época, remetido à presidente da companhia quase dois meses antes, o qual apontava para inconformidades de governança corporativa e o possível suborno (ICDR, 2018).

Dessa feita, as demandadas deram continuidade ao acordo inicial por meio da segunda novação que, como observaram os árbitros, constituiu negócio jurídico obviamente novo e não inclui as pessoas alegadamente envolvidas na oferta ou recebimento de propina. Ao proceder nesses termos, as demandadas ratificaram o primeiro contrato de afretamento e as obrigações comerciais dele decorrentes:

O Tribunal atribuiu sérias considerações às acusações de que o Sr. Su, ${ }^{24}$ o Sr. Padilha e o Sr. Bragg, entre outros, estiveram envolvidos em suborno para obter o DSA [o contrato]. Quanto aos Srs. Su e Padilha, nenhuma evidência convincente mostra que as demandantes tiveram conhecimento do suborno. Com relação ao Sr. Bragg, ${ }^{25}$ a situação é menos clara. Qualquer que seja a

24 De acordo com a defesa técnica das demandadas, o envolvimento do Sr. Su no pagamento de propina e a ciência de sua participação por parte da diretoria executiva da Vantage era prova suficiente para provar o envolvimento ao menos indireto da Vantage em práticas ilícitas. Para o tribunal, porém, não restou comprovado que as demandantes tinham conhecimento da intermediação e possível prática de crime por parte do então diretor da TMT.

25 Relativamente ao Sr, Bragg, a defesa da Petrobras tratou de imputar conhecimento e participação na negociação de vantagens ilícitas para a obtenção do contrato de afretamento. A partir dos convites pessoais feitos pela diretoria internacional, o Sr. Bragg compareceu a uma série de reuniões convocadas por agentes envolvidos no esquema de corrupção e que resultaram em negociações paralelas e contemporâneas ao processo de contratação formal para que melhorasse as propostas por ele apresentadas e, ao final, como de fato ocorreu, figurasse no topo do ranking para a celebrar o contrato com a 
situação com relação ao Sr. Bragg, novações subsequentes e emendas formaram novos contratos, não atingidos por suborno, se é que houve algum (ICDR, 2018, p. 59, grifou-se).

Nesse ponto, verifica-se que os árbitros utilizaram linguagem que expressa a ausência de clareza sobre a participação, ou não, de Paul Bragg no esquema de corrupção que a Petrobras, como é cediço, tentou provar naquele procedimento.

A brevíssima, porém preocupante indicação de que a incerteza quanto à atuação de Bragg não se apresentou como óbice à resolução do caso, uma vez que a solução jurídica da qual se lançou mão foi outra (a estruturação da cadeia contratual e o consequente impedimento à anulação) revela que os administradores do conflito perderam a oportunidade de aclarar quais elementos dos autos apontaram para a possibilidade concreta de envolvimento direto desse executivo, central ao caso, e o porquê da falta de clareza ter sido utilizada em prejuízo da Petrobras na decisão final.

Nas demonstrações financeiras de 2018, apresentadas em 2019, após a finalização da disputa perante o órgão arbitral, a companhia relatou o processo nos seguintes termos, e deu conta das fases sucessivas e estratégias que procuraria empregar para questionar o decisum:

O Tribunal Arbitral formado por três árbitros decidiu por maioria, com um voto divergente, que a Vantage tem direito a US $\$ 622,02$ milhões, acrescido de juros compostos de 15,2\%, a título de ressarcimento pela rescisão antecipada do contrato de serviços de perfuração da sonda Titanium Explorer. No dia 02/07/2018, a Vantage ajuizou ação de confirmação da sentença arbitral perante a Corte Federal do Texas. Em 31/08/2018, a Petrobras contestou a ação e ajuizou ação anulatória da sentença arbitral, inclusive com fundamento no voto divergente

Petrobras. Não obstante o envolvimento direto, para o tribunal, a possibilidade de que o diretor tenha consentido com a corrupção não produziu efeito prático sobre o sentido de julgamento. 
que reconheceu terem sido negadas as proteções fundamentais do devido processo legal à Petrobras. Em 27/08/2018, o Judiciário holandês deferiu medida cautelar em favor da Vantage, bloqueando eventuais valores e bens devidos à Petrobras, decorrentes de obrigações existentes por algumas de suas subsidiárias sediadas na Holanda, até 27/08/18, limitadas ao valor de US\$ 684 milhões. A medida também alcança as ações das subsidiárias Petrobras Netherlands B.V. e Petrobras International Braspetro B.V. Em 15/11/2018, a Vantage moveu ação de reconhecimento da sentença arbitral perante o Poder Judiciário Holandês (Petrobras, 2019c, pp. 110-111).

Revisando-se o arrazoado concludente, percebe-se que o tribunal arbitral julgou o relatório da CIA Época como prova bastante do conhecimento da Petrobras S.A. a respeito de ilícitos na contratação da Vantage com vistas a decidir que a anulabilidade do negócio jurídico restou impraticável a partir da segunda novação a pessoas jurídicas diversas, ao passo que repetiu, em diversos trechos da sentença, que "as demandadas não provaram a responsabilidade da Vantage (diretamente ou por imputação), por atos de suborno ou corrupção" (ICDR, 2018, p. 67). Sob esse prisma, o valor probatório do mesmo documento mostra-se divergente na interpretação de fatos conexos.

Outrossim, impende reconhecer que o motivo mais latente para a rescisão unilateral do contrato, a julgar pela extensão da argumentação jurídica e reafirmações constantes direcionadas à sociedade e aos investidores, justificando a medida drástica aplicada pelo Sistema Petrobras, foi a confirmação, no âmbito da Operação Lava Jato, de que a negociação envolveu crimes de corrupção, em detrimento das propaladas inadequações técnicas da Vantage a boas práticas do ramo.

Tem-se, ademais, que o conhecimento da existência de acordo de colaboração premiada firmado pelo Ministério Público Federal e o operador que atuou na defesa de interesses da Vantage, Hamylton Padilha, apresentou-se como impeditivo para que ao depoimento da testemunha fosse atribuído valor probante, dado o clarividente interesse em funcionar de modo a reduzir a pena de reclusão a ele creditada. 
Mesmo com o descortinar da corrupção na contratação original, pelo Poder Judiciário brasileiro, para o tribunal arbitral, a evolução da cadeia de contratos entre novos agentes, seguramente ligados aos anteriores, mas tratando-se de negócios jurídicos diversos e sem a participação dos alegados perpetradores de condutas ilícitas, tornou os instrumentos válidos, passíveis de ratificação e, por isso, exequíveis.

\section{CONCLUSÃO}

O caso do navio-sonda Titanium Explorer evidenciou um círculo de corrupção no Sistema Petrobras para revelar agentes criminosos e seu modo de operação e, em verdade, reposicionou o setor de inteligência investigativa vinculado à Justiça Federal após a abertura da Operação Lava Jato. Foi, como se depreende, um dos nós principais no desmonte do esquema de contratações públicas fraudulentas e, após a condenação dos acusados de terem participado da contratação da Vantage, motivo de rescisão contratual prematura. Por conseguinte, transformou-se em controvérsia comercial internacional resolvida por meio da arbitragem.

Nesse diapasão, a repercussão do caso Vantage investigado na Lava Jato sobre o procedimento arbitral entre Vantage e Petrobras, especificamente no que concerne à argumentação de defesa das demandadas, ocorreu de maneira limitada. Restou explicitado que o tribunal arbitral atribuiu às demandadas o onus probatório relativamente à elucidação da propalada corrupção das demandantes, fosse ela direta ou por imputação, de forma a obter o contrato de perfuração, na esteira da linha argumentativa que defendia o seguinte: caso houvesse prova do envolvimento ou conluio da Vantage no pagamento de propina, pelo direito aplicável o contrato de perfuração firmado em 2009 padeceria de nulidade, o que, em tese, impediria a tentativa de execução do contrato em 2015.

Não obstante a multiplicidade de elementos de prova reunidos pela Operação Lava Jato no Brasil, não há, na sentença arbitral, nem 
nos anexos de síntese argumentativa das partes, menção expressa à Operação Lava Jato (Operation Car Wash). Indiretamente, porém, colhe-se que as demandadas se valeram de um julgamento da Justiça Federal o qual, segundo elas, seria a prova conclusiva da prática de suborno pela Vantage previamente à assinatura do contrato do Titanium Explorer. Mencionado documento não foi objeto de maiores comentários na decisão final, para além desse relato do que disseram as demandadas a respeito da prova na qual firmavam sua estratégia defensiva.

Nesse ponto cabe verificar que a investigação pelo Poder Judiciário dos crimes contra o Sistema Petrobras no acordo com a Vantage sequer colaborou em grau mínimo para o arrazoado final do painel na apreciação da posição da Petrobras. Para além disso: a Operação Lava Jato funcionou em desfavor da estratégia da Petrobras na tentativa de fornecer prova testemunhal.

Isso ocorreu porque as demandantes sustentaram a impossibilidade de aceitar como verdadeiro o depoimento da única testemunha da Petrobras ouvida para esclarecer o pagamento de propina e o envolvimento da Vantage, tendo por base o desinteresse do doleiro Hamylton Padilha em cumprir o dever de veracidade típico da testemunha uma vez que ele havia firmado acordo de colaboração premiada com o Ministério Público Federal.

Minada por completo a estratégia probatória que apresentou a Petrobras para comprovar conhecimento e atuação da Vantage na forma ilícita empregada na obtenção do contrato, o tribunal voltou-se, então, ao relatório final apresentado pela CIA Época para construir seu arrazoado a respeito da evolução da cadeia contratual, mediante novações e emendas, a pessoas jurídicas distintas das alegadamente envolvidas no oferecimento e recebimento de propina.

Reitera-se que a utilização do documento acima referido como prova de que a Petrobras se manteve na relação comercial com a Vantage após auditoria que denunciou o esquema de corrupção para declará-la impedida de alegar anulabilidade do contrato com fundamento na ilicitude, contraposta à não utilização desse mesmo 
documento como prova do envolvimento de Paul Bragg no esquema, revela possível tendência.

O sentido de julgamento, portanto, foi de que a novação e emendas posteriores à submissão do Relatório Final pela CIA Época à Presidente da S.A. impediu a pretensão de anular o pacto primevo. $\mathrm{Na}$ visão dos árbitros, tornou-se clarividente que o exercício válido e regular do direito de requerer a anulação do contrato com fundamento na fraudulenta negociação foi deliberadamente preterido (e, frise-se, por uma série de inoperâncias da Administração Pública). Por essas razões, tem-se que os objetivos de pesquisa foram atingidos e a hipótese de trabalho corroborada na medida em que a repercussão da Operação Lava Jato foi limitada e tornou por prejudicar a posição das demandadas na arbitragem comercial internacional, o que lhes rendeu uma sentença condenatória em valor que superou, à época da remessa às partes, US\$ 622 milhões.

\section{REFERÊNCIAS}

BRASIL. Lei n. 2004, de 3 de outubro de 1953. Dispõe sobre a Política Nacional do Petróleo e define as atribuições do Conselho Nacional do Petróleo, institui a Sociedade Anônima, e dá outras providências. Diário Oficial da União, Rio de Janeiro, p. 16705, col. 3, 3 out. 1953.

BRASIL. Lei n. 9.478, de 6 de agosto de 1997. Dispõe sobre a política energética nacional, as atividades relativas ao monopólio do petróleo, institui o Conselho Nacional de Política Energética e a Agência Nacional do Petróleo e dá outras providências. Diário Oficial da União, Brasília, p. 16925, col. 1, 7 ago 1997.

CIA - COMISSÃO INTERNA DE APURAÇÃO ÉPOCA. Relatório Final da Comissão Interna de Apuração instituída pelo DIP PRESIDÊNCIA 121/2013: Reportagem revista Época - edição nº 794. Rio de Janeiro: Petrobras, 2013. Disponível em: https://politica.estadao.com.br/ blogs/fausto-macedo/wp-content/uploads/sites/41/2015/08/1_ANEXO56-relatorio.pdf. Acesso em: 13 mai 2021. 
COAF - CONSELHO DE CONTROLE DE ATIVIDADES FINANCEIRAS. COAF divulga balanço das atividades de inteligência financeira realizadas em 2018. Ministério da Fazenda, 2018. Disponível em: https:// www.gov.br/fazenda/pt-br/assuntos/noticias/2018/dezembro/coaf-divulga-balanco-das-atividades-de-inteligencia-financeira-realizadas-em-2018. Acesso em: 13 mai 2021.

DI PIETRO, Maria Sylvia Zanella. Direito Administrativo. 27 ed. São Paulo: Atlas, 2014.

ECOSTEGUY, Diego. As denúncias do operador do PMDB na Petrobras. Revista Época. Edição 794, de 12 de agosto de 2013. Disponível em: https:// epoca.globo.com/tempo/noticia/2013/08/denuncias-do-boperador-do-pmdbb-na-petrobras.html. Acesso em: 13 mai 2021.

ENTELMAN, Remo F. Teoría de conflictos: hacia un nuevo paradigma. Barcelona: Gedisa, 2005.

FINANCIAL TIMES LEXICON. Definition of invoice. Financial Times, 2019. Disponível em: http://lexicon.ft.com/Term?term=invoice. Acesso em: 13 mai 2021.

GLOBENEWSWIRE. Vantage Drilling Company recebe notificação de término de contrato de perfuração. Houston, 2015. Disponível em: http://globenewswire.com/news-release/2015/09/02/1116480/0/pt/Vantage-Drilling-Company-recebe-notificação-de-término-de-contrato-de-perfuração.html. Acesso em:13 mai 2021.

ICDR - INTERNATIONAL CENTRE FOR DISPUTE RESOLUTION. Vantage v. Petrobras ICDR Case No. 01-15-0004-8503. Final Award and Dissent. Houston, Texas, USA, 2018. Disponível em: https:// www.transnational-dispute-management.com/legal-and-regulatory-detail. asp?key=20646. Acesso em: 13 mai 2021.

JUSTIÇA FEDERAL. Ação Penal no 5039475-50.2015.4.04.7000/PR. Sentença de 1 de fevereiro de 2016. Juiz Federal prolator Sérgio Fernando Moro. 13. ${ }^{a}$ Vara Federal Criminal de Curitiba, 2016. Disponível em https:// www.conjur.com.br/dl/sentenca-zelada-outro-navio-sonda.pdf. Acesso em: 13 mai 2021.

MINISTÉRIO PÚBLICO FEDERAL. Lava Jato: MPF denuncia Jorge Luiz Zelada e mais cinco por corrupção e outros crimes. 6 de agosto de 2015. MPF, 2015. Disponível em: http://www.mpf.mp.br/pr/sala-de-imprensa/ 
noticias-pr/lava-jato-mpf-denuncia-jorge-luiz-zelada-e-mais-cinco-por-corrupcao-evasao-de-divisas-e-lavagem-de-dinheiro-1. Acesso em: 13 mai 2021.

MINISTÉRIO PÚBLICO FEDERAL. Caso Lava Jato: entenda o caso. MPF, 2019a. Disponível em: http://www.mpf.mp.br/grandes-casos/lava-jato/entenda-o-caso. Acesso em: 13 mai 2021.

MINISTÉRIO PÚBLICO FEDERAL. Caso Lava Jato: resultados. MPF, 2019b. Disponível em: http://www.mpf.mp.br/grandes-casos/lava-jato/ resultados. Acesso em: 13 mai 2021.

PETROBRAS - PETRÓLEO BRASILEIRO S.A. Petrobras questionará decisão arbitral proferida por maioria em arbitragem iniciada pela Vantage. Comunicados e Fatos Relevantes. Rio de Janeiro, 3 de julho de 2018. Petrobras, 2018a. Disponível em: http://www.investidorpetrobras. com.br/pt/comunicados-e-fatos-relevantes/petrobras-questionara-decisao-arbitral-proferida-por-maioria-em-arbitragem-iniciada-pela-vantage. Acesso em: 13 mai 2021.

PETROBRAS - PETRÓLEO BRASILEIRO S.A. Informações Trimestrais - ITR: Em 31 de março de 2018 e relatório sobre a revisão de informações trimestrais. Rio de Janeiro, Petrobras, 2018b. Disponível em: https://mz-filemanager.s3.amazonaws.com/25fdf098-34f5-4608-b$7 \mathrm{fa}-17 \mathrm{~d} 60 \mathrm{~b} 2 \mathrm{de} 47 \mathrm{~d} /$ central-de-resultadoscentral-de-downloads/a5d1a8cef1828b648a9f0579c862ca798f89bf9777109ce4a2cd47278edd3a16/demonstracoes_financeiras_trimestrais_1t18_ifrs_r\$.pdf. Acesso em: 13 mai 2021. PETROBRAS - PETRÓLEO BRASILEIRO S.A. Petrobras questionará decisão arbitral proferida por maioria em arbitragem iniciada pela Vantage. Petrobras: Rio de Janeiro, 2018c. Disponível em: https://www. agenciapetrobras.com.br/Materia/ExibirMateria?p_materia=980387. Acesso em: 13 mai 2021.

PETROBRAS - PETRÓLEO BRASILEIRO S.A. Presença global. Rio de Janeiro: Petrobras: 2019a. Disponível em: http://www.petrobras.com. br/pt/presenca-global/. Acesso em: 13 mai 2021.

PETROBRAS - PETRÓLEO BRASILEIRO S.A. Relatório Anual 2018. Relato integrado. 2019b. Disponível em: https://mz-filemanager.s3.amazonaws.com/25fdf098-34f5-4608-b7fa-17d60b2de47d/relatorios-anuaiscentral-de-downloadskit-do-investidor/5eb1b9fee9356aba87ab53b1463b- 
20c7e3e34fe2c1e624b52cfdf00e2ef27f51/relatorio_anual_2018.pdf. Acesso em: 13 mai 2021.

PETROBRAS - PETRÓLEO BRASILEIRO S.A. Financial statements: December 31, 2018, 2017 and 2016 with report of independent registered public accounting firm. Petrobras: Rio de Janeiro, 2019c. Disponível em: https://mz-filemanager.s3.amazonaws.com/25fdf098-34f5-4608-b$7 \mathrm{fa}-17 \mathrm{~d} 60 \mathrm{~b} 2 \mathrm{de} 47 \mathrm{~d} /$ central-de-resultadoscentral-de-downloads $/ 505 \mathrm{cde}-$ 7597f35ead39b69b0f9d9baa642e82573ad8f30ed1d05fadb29a96071e/2018_ annual_financial_statements_ifrs_in_usd.pdf. Acesso em: 13 mai 2021.

POLÍCIA FEDERAL. Operação Lava Jato desarticula rede de lavagem de dinheiro em 7 estados. Curitiba: Agência de notícias, 2014. Disponível em: http://www.pf.gov.br/agencia/noticias/2014/03/operacao-lava-jato-desarticula-rede-de-lavagem-de-dinheiro-em-7-estados. Acesso em: 13 mai 2021.

POLÍCIA FEDERAL. Operação Lava Jato. Agência de notícias, 2016. Disponível em http://www.pf.gov.br/agencia/noticias/lava-jato/. Acesso em: 13 mai 2021.

POLÍCIA FEDERAL. Fases da Operação Lava Jato. Ministério da Justiça e Segurança Pública, 2018. Disponível em http://www.pf.gov.br/imprensa/ lava-jato/fases-da-operacao-lava-jato-1/. Acesso em: 13 mai 2021.

SANTOS, Ricardo Soares Stersi dos. Mercosul e arbitragem internacional comercial: aspectos gerais e algumas possibilidades. 1996. Dissertação (Mestrado) - Universidade Federal de Santa Catarina, Centro de Ciencias Juridicas. Disponível em: https://repositorio.ufsc.br/bitstream/ handle/123456789/76930/104390.pdf?sequence=1\&isAllowed=y. Acesso em: 13 mai 2021.

\section{JOANA STELZER}

Pós-Doutora em Direito pela Universidade de São Paulo - USP. Doutora e Mestre em Direito, na área de Relações Internacionais pela Universidade Federal de Santa Catarina (UFSC). Professora credenciada no Programa de Pós-Graduação em Direito 
da Universidade Federal de Santa Catarina - PPGD/CCJ/UFSC (Santa Catarina, Brasil).

Endereço profissional: Programa de Pós-Graduação em Direito, Universidade Federal de Santa Catarina, Centro de Ciências Jurídicas, Campus Universitário, s/n - Trindade Florianópolis - SC, CEP 88040-900, Brasil.

ORCID ID: https://orcid.org/0000-0002-9503-4080

E-MAIL: contatojoana@yahoo.com.br

\section{ALISSON GUILHERME ZEFERINO}

Doutorando pelo Programa de Pós-graduação em Direito da Universidade Federal de Santa Catarina - PPGD/CCJ/UFSC (Santa Catarina, Brasil). Mestre em Direito pela Universidade Federal de Santa Catarina (2020). Bacharel em Direito pela Universidade Comunitária da Região de Chapecó (2017). Bolsista Capes-Proex. Endereço profissional: Programa de Pós-Graduação em Direito, Universidade Federal de Santa Catarina, Centro de Ciências Jurídicas, Campus Universitário, s/n - Trindade Florianópolis - SC, CEP 88040-900, Brasil.

ORCID ID: https://orcid.org/0000-0002-2052-3365

E-MAIL: alissontwo@gmail.com

Recebido: 13/05/2021

Aceito: 19/01/2022

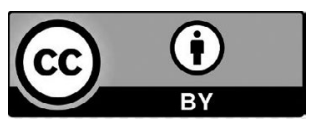

Este trabalho está licenciado sob uma licença Creative Commons Attribution 4.0 International License. 
Autores e autoras cedem à Revista Sequência direitos exclusivos de primeira publicação, ficando o trabalho licenciado sob a Creative Commons Attribution 4.0 International License. A licença autoriza que terceiros remixem, adaptem e ou criem a partir do trabalho publicado, indicando o crédito ao trabalho original e sua publicação inicial. Os autores têm permissão para assumir contratos adicionais em separado, com distribuição não exclusiva da versão publicada na Revista Sequência, indicando, de todo modo, a autoria e publicação inicial neste periódico. 